\title{
Patient and parent preferences for characteristics of prophylactic treatment in hemophilia
}

\author{
This article was published in the following Dove Press journal: \\ Patient Preference and Adherence \\ 23 November 2015 \\ Number of times this article has been viewed
}

\section{Roberto Furlan' Sangeeta Krishnan ${ }^{2}$ Jeffrey Vietri ${ }^{3}$}

'Advanced Methods, Kantar Health, Epsom, Surrey, UK; ${ }^{2}$ Global Health Economics and Outcomes Research, Biogen, MA, USA; ${ }^{3}$ Health Outcomes, Kantar Health, Milan, Italy
Correspondence: Jeffrey Vietri Kantar Health, 700 Dresher Road, Horsham, PA 19044, USA

$\mathrm{Tel}+$ I 484442 I437

Email Jeffrey.vietri@kantarhealth.com
Introduction: New longer-acting factor products will potentially allow for less frequent infusion in prophylactic treatment of hemophilia. However, the role of administration frequency relative to other treatment attributes in determining preferences for prophylactic hemophilia treatment regimens is not well understood.

Aim: To identify the relative importance of frequency of administration, efficacy, and other treatment characteristics among candidates for prophylactic treatment for hemophilia A and B.

Method: An Internet survey was conducted among hemophilia patients and the parents of pediatric hemophilia patients in Australia, Canada, and the US. A monadic conjoint task was included in the survey, which varied frequency of administration (three, two, or one time per week for hemophilia A; twice weekly, weekly, or biweekly for hemophilia B), efficacy (no bleeding or breakthrough bleeding once every 4 months, 6 months, or 12 months), diluent volume ( $3 \mathrm{~mL}$ vs $2.5 \mathrm{~mL}$ for hemophilia A; $5 \mathrm{~mL}$ vs $3 \mathrm{~mL}$ for hemophilia B), vials per infusion (2 vs 1 ), reconstitution device (assembly required vs not), and manufacturer (established in hemophilia vs not). Respondents were asked their likelihood to switch from their current regimen to the presented treatment. Respondents were told to assume that other aspects of treatment, such as risk of inhibitor development, cost, and method of distribution, would remain the same.

Results: A total of 89 patients and/or parents of children with hemophilia A participated; another 32 were included in the exercise for hemophilia B. Relative importance was $47 \%, 24 \%$, and $18 \%$ for frequency of administration, efficacy, and manufacturer, respectively, in hemophilia A; analogous values were $48 \%, 26 \%$, and $21 \%$ in hemophilia B. The remaining attributes had little impact on preferences.

Conclusion: Patients who are candidates for prophylaxis and their caregivers indicate a preference for reduced frequency of administration and high efficacy, but preferences were more sensitive to administration frequency than small changes in annual bleeding rate.

Keywords: prophylaxis, conjoint analysis, treatment preferences, breakthrough bleeds, frequency of administration

\section{Introduction}

Individuals with severe hemophilia are at risk for spontaneous bleeding into soft tissues and joints. Bleeding into a joint can initiate a cycle of increased risk of local bleeding, pain, and joint damage, resulting in irreversible arthropathy and lack of mobility. ${ }^{1}$ The consequences of hemophilia can prevent the individual from living a normal and productive life and also impact the family and those around them as the burden of providing care increases. ${ }^{2-4}$

Hemophilia is treated through infusion of the missing clotting factor, factor VIII (FVIII) in hemophilia A, and factor IX (FVIX) in hemophilia B. Multiple treatment paradigms exist, which fall into two broad categories. The first is referred to as episodic or on-demand treatment, wherein factor is infused to treat a bleeding event. 
The second strategy is prophylactic treatment, wherein factor is infused proactively according to a prescribed schedule. Individuals can also use a mixed strategy, using prophylaxis during periods of time when participating in sports or other activities where the risk of injury is higher and treating on demand at other times. Evidence from both controlled trials and observational studies demonstrates superior outcomes in prophylaxis compared to episodic treatment. ${ }^{5-13}$ Indeed, severe hemophilia patients who are maintained on prophylaxis from an early age can maintain nearly normal joint health. ${ }^{9}$ Despite the evidence supporting the efficacy of prophylaxis, it may be under-used in some countries, including the US. ${ }^{14,15}$

All currently available clotting factor products have proven efficacious in preventing and stopping bleeds, but all pose similar difficulties for the patient since frequent infusions are required to maintain adequate serum factor levels. Maintaining a prophylactic regimen can be a burden in itself due to venous puncture, time spent infusing clotting factor, ${ }^{1,7}$ and considerable monetary costs. These aspects of prophylaxis discourage adequate and appropriate use of the treatment strategy, making some physicians reluctant to prescribe prophylaxis. ${ }^{15-17}$ The difficulties associated with maintaining a prophylactic infusion regimen may result in patient nonadherence ${ }^{18-21}$ and nonpersistence, ${ }^{1,22}$ leaving the patient at risk for bleeding and consequent joint damage. Barriers related to the frequency of administration may be reduced with the introduction of longer-acting factor products as these should allow for reduced frequency of venous puncture and total time spent infusing. ${ }^{23}$

Given the evidence for the superiority of prophylaxis in long-term clinical outcomes and the difficulties of maintaining adherence to prophylaxis, it is important to understand how individuals with hemophilia - and the parents of children with hemophilia - value the different features of potential treatments and what types of products and regimens may facilitate adherence and persistence with prophylaxis. One way to better understand the importance of treatment attributes is through conjoint analysis. This technique can be used to elicit the relative importance that respondents place on different features of a treatment by observing how they trade off different levels of one feature against those of another. There are several studies exploring patient preferences for different hemophilia treatments through conjoint analysis, including studies of physician preferences, ${ }^{24-27}$ pharmacist preferences, ${ }^{26,27}$ and patient preferences. ${ }^{26-28}$ However, these have not addressed the relationship between frequency of administration and frequency of bleeds in a sample of patients who are candidates for prophylaxis, which is important to understand as new longer-acting factor products become available. The current study was conducted to assess how both adult candidates for prophylaxis and parents of pediatric candidates for prophylaxis value different features of treatment when considering whether to switch to such a treatment.

\section{Method}

\section{Sample}

The US, Canada, and Australia were included in the study to allow for the inclusion of multiple countries with similar prophylaxis rates and per capita factor consumption. ${ }^{29}$ Respondents were recruited through a hemophilia patient panel in the US, and respondents in Canada and Australia were directed to the survey through links on hemophilia patient association websites in those countries. Respondents were either adult men with hemophilia or the parent of a son with hemophilia. Parents who had more than one son with hemophilia were told to answer based on their eldest son. Additional inclusion criteria were based on the patient's characteristics, that is, the respondent himself in the case of adult patients and the son with hemophilia in the case of a parent respondent. These were report of moderate or severe hemophilia A or B, no inhibitors, and current use of one of two hemophilia treatment strategies: 1) prophylactic treatment or 2) episodic treatment with at least one bleeding episode per month. American and Australian respondents were required to read and write in English, and Canadian respondents could complete the survey in either English or French. This study was reviewed and approved by Essex Institutional Review Board (Lebanon, NJ, USA), and all respondents provided informed consent to participate. The study questionnaire was administered via the internet. Data were collected from November 2012 through March 2013.

\section{Preference elicitation}

Conjoint exercises are now commonly used to understand what aspects or features of treatments are valued by patients, physicians, and parents. In these exercises, respondents make a series of choices or ratings about hypothetical treatment options, which vary across different attributes that may play a role in the decision, such as cost, efficacy, or risk of side effects. The set of hypothetical options is constructed to allow the levels of each attribute to vary across options, for example, some treatments cost more, some are more efficacious, and the role of each attribute in the preference for treatment can be derived from the pattern of choices. 
The conjoint model used in this study employed full profile conjoint cards. A full profile card represents a single hypothetical treatment option, and the option is described by one level (ie, value) for each attribute included in the study. We identified six attributes to describe the potential treatment options for both hemophilia A and B: frequency of administration, efficacy in terms of breakthrough bleeding episodes, diluent volume, vials per infusion, reconstitution device, and manufacturer (Table 1). Attributes were the same for both hemophilia A and B, but some of the levels for the frequency of administration attribute and diluent volume differed for the two conditions consistent with current practice. The attributes and levels were selected based on the review of previous research and analysis of the features of currently available products and new market entries. Respondents were told to assume that each product had been available for at least a year, viral safety and risk of inhibitor development were similar to those of the current treatment, and cost would not be a factor in the decision. Australian respondents were also informed that the method of distribution would be the same as with their current factor product.

Treatment options were presented to respondents according to a monadic approach (one-at-a-time) as in Figure 1. Respondents were asked to assess the likelihood to switch from the current treatment to each hypothetical treatment profile using a rating scale from $0 \%$ ("not at all likely")

Table I Attribute descriptions and levels by type of hemophilia

\begin{tabular}{|c|c|c|}
\hline \multirow{2}{*}{$\begin{array}{l}\text { Attribute } \\
\text { description }\end{array}$} & \multicolumn{2}{|l|}{ Attribute levels } \\
\hline & Hemophilia A & Hemophilia B \\
\hline $\begin{array}{l}\text { Frequency of } \\
\text { administration } \\
\text { on prophylaxis }\end{array}$ & $\begin{array}{l}\text { Three times a week } \\
\text { Twice a week } \\
\text { Once a week }\end{array}$ & $\begin{array}{l}\text { Twice a week } \\
\text { Once a week } \\
\text { Once every 10-14 days }\end{array}$ \\
\hline \multirow[t]{2}{*}{ Diluent volume } & $\begin{array}{l}3 \mathrm{~mL} \\
2.5 \mathrm{~mL}\end{array}$ & $\begin{array}{l}5 \mathrm{~mL} \\
3 \mathrm{~mL}\end{array}$ \\
\hline & \multicolumn{2}{|c|}{ Either hemophilia A or B } \\
\hline $\begin{array}{l}\text { Efficacy: number } \\
\text { of breakthrough } \\
\text { bleeds while on } \\
\text { prophylaxis }\end{array}$ & $\begin{array}{l}\text { One bleed } / 4 \text { months } \\
\text { One bleed } / 6 \text { months } \\
\text { One bleed/year } \\
\text { None }\end{array}$ & \\
\hline $\begin{array}{l}\text { Number of vials } \\
\text { per infusion }\end{array}$ & \multicolumn{2}{|l|}{ Two vials per infusion } \\
\hline $\begin{array}{l}\text { Reconstitution } \\
\text { device }\end{array}$ & \multicolumn{2}{|c|}{$\begin{array}{l}\text { Dual chamber syringe that contains the diluent and } \\
\text { drug in a single device; no assembly required; easy } \\
\text { mixing }\end{array}$} \\
\hline Manufacturer & \multicolumn{2}{|c|}{$\begin{array}{l}\text { The manufacturer of this product is new to } \\
\text { hemophilia, and you are unfamiliar with it } \\
\text { You are familiar with the manufacturer of this } \\
\text { product and the products it offers in hemophilia }\end{array}$} \\
\hline
\end{tabular}

to $100 \%$ ("extremely likely"). This design was selected over a discrete choice experiment where respondents choose between two or more alternatives to more closely reflect the nature of the treatment decision for these respondents, as all patients were currently treated and new treatment options would likely be evaluated relative to their current regimen rather than against another alternative. The use of a monadic task also had the benefit of lower respondent burden as respondents were required to read and understand only one treatment at a time rather than two or more, and use of a scale allowed for the expressions of finer-grained distinctions between options than relying on binary switch versus do not switch decisions.

We created a $D$-efficient block design for a full profile experiment ( $D$-efficiency 99.9\%): 15 different versions (blocks) of ten different treatment profiles were generated from the full set of $2^{4} \times 3 \times 4$ possible treatment scenarios. ${ }^{30}$ Each respondent was randomly assigned to one version and was exposed to all ten treatment profiles within the selected version. Such a design allows for robust estimation of the effect of each attribute given the anticipated sample size. In addition to the set of ten scenarios, each respondent was also exposed to a duplicate profile to allow testing for consistency of responses.

\section{Statistical analysis}

Responses of adults with hemophilia and parents of children with hemophilia were included in the same analysis due to limited sample size.

The conjoint framework adopted for this project assumes that a respondent's rating of each scenario can be decomposed into the sum of contributions from the various attributes. For each attribute, the contribution is the part-worth associated to the level describing the scenario. In other words, the part-worth is the marginal utility of the attribute in the individual's rating of the conjoint scenario. The main outcome of conjoint analysis is the estimation of the partworth associated to each level of each attribute considered in the conjoint design.

A hierarchical Bayes (HB) regression was used to estimate the part-worth utilities associated with the levels of the attributes included in the study. ${ }^{31}$ This approach avoids potential estimation bias from unobserved preference heterogeneity in rating conjoint by estimating a distribution of preferences for each parameter in the model. HB part-worths are estimated for each respondent (individual-level analysis). The coefficients from this regression model were also the basis for the estimation of the relative importance of the attributes of the study. HB coefficient estimation was conducted 


\begin{tabular}{|c|c|}
\hline \multicolumn{2}{|c|}{ Scenario 1} \\
\hline Frequency of administration on prophylaxis & Once a week \\
\hline $\begin{array}{l}\text { Efficacy: number of breakthrough bleeds } \\
\text { while on prophylaxis }\end{array}$ & One bleed a year \\
\hline Number of vials required per infusion & Two vials per infusion \\
\hline Diluent volume & $3 \mathrm{~mL}$ \\
\hline Reconstitution device & $\begin{array}{l}\text { Dual chamber syringe which contains the diluent } \\
\text { and drug in a single device. No assembly required. } \\
\text { Easy mixing }\end{array}$ \\
\hline Manufacturer & $\begin{array}{l}\text { The manufacturer of this product is new to } \\
\text { hemophilia and you are unfamiliar with it }\end{array}$ \\
\hline
\end{tabular}

How likely would you be to have your son switched to this treatment option?

(Please select the appropriate percentage from 0 to 100 using the slider below.)

\begin{tabular}{llc}
$0 \%=\begin{array}{l}\text { not at all } \\
\text { likely }\end{array}$ & $\begin{array}{c}100 \%=\begin{array}{c}\text { extremely } \\
\text { likely }\end{array} \\
\text { likely }\end{array}$ \\
\hline
\end{tabular}

Figure I Sample treatment option and response scale for rating task.

using the package R-sw Conjoint and was run separately for hemophilia A and hemophilia B. ${ }^{32}$ Inconsistent respondents were identified using Kendall's tau rank correlation coefficient to measure the similarity between the observed and estimated ratings of each of the scenarios respondents have been exposed to. Low scores on this coefficient indicate an inconsistent relationship between attribute levels and preference ratings, so respondents with a coefficient $<0.55$ were excluded from further analysis. We considered respondents with a discrepancy $>40$ points in the rating score between the two duplicated scenarios to be excessive, and so these respondents were also excluded.

\section{Relative importance}

The importance score of an attribute is the difference between the part-worth utility associated with the best and worst level of the attribute. Scores were scaled so that the total importance over the six attributes added up to $100 \%$ and the scores for the various attributes were comparable. As a point of reference, if all six attributes were of equal importance in the likelihood to switch, then the importance score for each attribute would be $\sim 16.7 \%$ (ie, $100 \% / 6$ ). This is the standard approach for estimating relative importance scores in conjoint analysis and has been used since its original development. ${ }^{33}$

\section{Part-worth utilities of conjoint levels}

These are the marginal utilities of the levels in the individual's rating of the conjoint scenario. The part-worth figures themselves do not have an absolute meaning; rather, they were used to assess the impact of each level and compare across levels. In addition, when looking at any specific product profile, part-worth figures from various attributes and levels can be combined together and thus converted into likelihood for patients to indicate willingness to switch to the new product.

\section{Results}

\section{Respondent characteristics}

A total of 121 of $151(80 \%)$ respondents completed the survey and provided consistent responses in the conjoint section of the questionnaire. There were no statistically significant differences in the demographics between those with consistent and inconsistent responses (data not shown). Respondent characteristics are presented in Table 2. Approximately $70 \%$ of the included respondents were in the US, 74\% reported hemophilia A, almost all (96\%) indicated severe hemophilia, and $74 \%$ were currently using prophylactic treatment.

\section{Relative importance}

Three of the six attributes accounted for $>88 \%$ of the total impact of the elements included in the study on the treatment decision process in hemophilia A (Figure 2). Frequency of administration on prophylaxis was the main driver of preference among the attributes included in the exercise, with a relative importance of $47 \%$. The frequency of breakthrough bleeding, here drawn from the range of bleeding rates reported in clinical trials, ${ }^{3441}$ had a relative importance of 
Table 2 Respondent characteristics by type of hemophilia

\begin{tabular}{|c|c|c|}
\hline \multirow[t]{3}{*}{ Patient characteristics } & Hemophilia A & Hemophilia B \\
\hline & $(N=89)$ & $(\mathrm{N}=32)$ \\
\hline & n (\%) & n (\%) \\
\hline \multicolumn{3}{|l|}{ Country } \\
\hline Australia & $9(10 \%)$ & $5(16 \%)$ \\
\hline Canada & 15 (I7\%) & $5(16 \%)$ \\
\hline US & $65(73 \%)$ & 22 (69\%) \\
\hline \multicolumn{3}{|l|}{ Respondent type } \\
\hline Adult patient & $54(61 \%)$ & $21(66 \%)$ \\
\hline Parent of pediatric patient & 35 (39\%) & II (34\%) \\
\hline \multicolumn{3}{|l|}{ Mean age in years } \\
\hline Adults & 33.3 & 40.4 \\
\hline Pediatric patients & 10.5 & 11.2 \\
\hline \multicolumn{3}{|l|}{ Severity } \\
\hline Moderate & $3(3 \%)$ & $2(6 \%)$ \\
\hline Severe & $86(97 \%)$ & $30(94 \%)$ \\
\hline \multicolumn{3}{|l|}{ Treatment paradigm } \\
\hline Prophylaxis & 70 (79\%) & $20(63 \%)$ \\
\hline On-demand & 19 (21\%) & $12(38 \%)$ \\
\hline $\begin{array}{l}\text { Mean number of bleeds } \\
\text { in last year }\end{array}$ & 9.9 & 12.4 \\
\hline
\end{tabular}

$24 \%$, approximately half that of administration frequency. Whether the product came from an established manufacturer of hemophilia treatments had a similar impact on preference, with an importance of $18 \%$. Of the remaining attributes, number of vials and reconstitution device had a small and similar impact on the decision process, with $6 \%$ and $4 \%$ importance, respectively, while diluent volume accounted for $2 \%$.

Frequency of administration, efficacy, and manufacturer accounted for $95 \%$ of the total decision process for those considering treatments for hemophilia B (Figure 2). Frequency of administration was most closely related to preference, with a relative importance of $48 \%$. Frequency of breakthrough bleeds had a relative importance of $26 \%$, while the manufacturer had an importance of $21 \%$. The remaining attributes each had an importance of $<3 \%$.
The marginal utility results for treatment attributes are presented in Table 3. The preference weights for each level within each attribute were ordered as expected, with higher marginal utilities (indicating greater preference) associated with less frequent administration, less frequent bleeding, fewer vials per infusion, and a more familiar manufacturer.

\section{Discussion}

This study assessed the relative importance of treatment attributes among adults with hemophilia and parents of pediatric hemophilia patients in the decision to switch from their current regimen to a hypothetical prophylactic treatment regimen. In the context of the attribute levels included here - where the efficacy of different products results in at most three bleeding events per year and costs and risk of infection and inhibitor development are consistent across products - respondents' willingness to switch to a prophylactic regimen was primarily determined by how frequently they would need an infusion, followed by the rate of breakthrough bleeding. This was consistent across hemophilia A and B, suggesting that hemophilia $\mathrm{B}$ patients are just as motivated to reduce the frequency of infusion as hemophilia A patients, despite the fact that hemophilia A patients carry a higher burden for prophylaxis overall. Respondents also demonstrated a distinct preference for using the products created by an established manufacturer rather than a company new to hemophilia treatment. The other treatment attributes had a negligible effect on the decision.

The magnitude of the part-worth utilities suggests that respondents view the impact of the small differences in annual bleed rate to be of limited importance in the context of eliminating a weekly administration. Presently this is a moot point as clinical trials of long-acting factor regimens have demonstrated mean annualized bleeding rates similar to those demonstrated by conventional factor products (eg, in hemophilia $\mathrm{A}^{34-36}$ and in hemophilia $\mathrm{B}^{37-41}$ ). Indeed, among
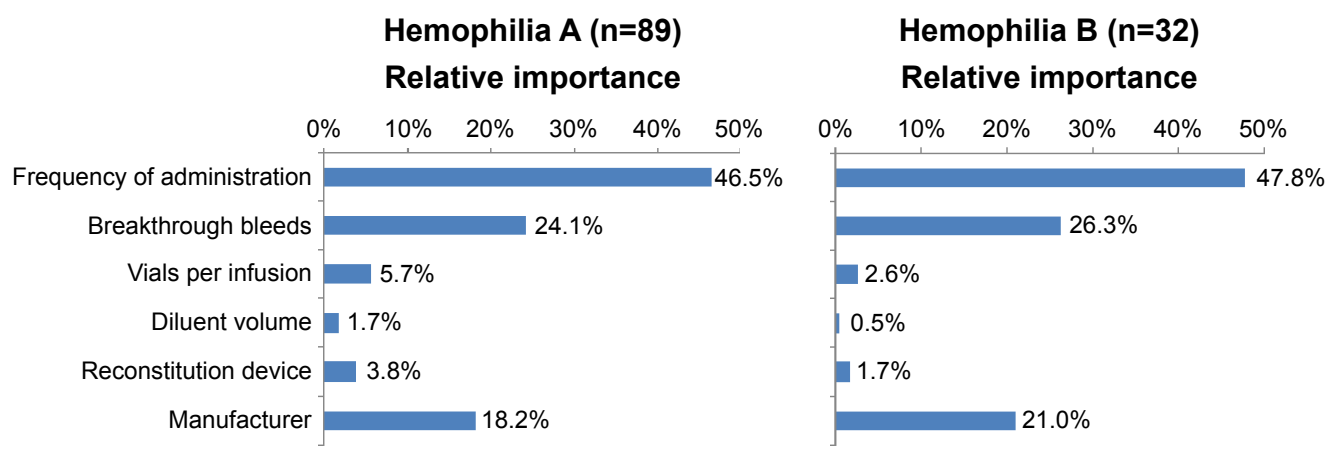

Figure 2 Relative importance of treatment attributes by type of hemophilia. 
Table 3 Part-worth utilities of treatment attributes

\begin{tabular}{|c|c|c|c|c|}
\hline \multirow[t]{2}{*}{ Attribute and level } & \multicolumn{2}{|c|}{ Hemophilia A } & \multicolumn{2}{|c|}{ Hemophilia B } \\
\hline & Utility & SE & Utility & SE \\
\hline \multicolumn{5}{|l|}{ Frequency of administration on prophylaxis } \\
\hline Three times a week & -0.91 & 0.05 & N/A & $\mathrm{N} / \mathrm{A}$ \\
\hline Twice a week & -0.00 & 0.03 & -0.58 & 0.07 \\
\hline Once a week & 0.91 & 0.16 & -0.01 & 0.07 \\
\hline Once every $10-14$ days & $N / A$ & $\mathrm{~N} / \mathrm{A}$ & 0.60 & 0.07 \\
\hline \multicolumn{5}{|l|}{ Efficacy: number of breakthrough bleeds while on prophylaxis } \\
\hline None & 0.47 & 0.04 & 0.14 & 0.06 \\
\hline One per year & 0.32 & 0.03 & 0.29 & 0.04 \\
\hline Two per year & -0.24 & 0.02 & -0.10 & 0.04 \\
\hline Three per year & -0.53 & 0.05 & -0.48 & 0.10 \\
\hline \multicolumn{5}{|l|}{ Number of vials required per infusion } \\
\hline One vial per infusion & 0.14 & 0.02 & 0.05 & 0.06 \\
\hline Two vials per infusion & -0.14 & 0.02 & -0.05 & 0.06 \\
\hline \multicolumn{5}{|l|}{ Diluent volume } \\
\hline $2.5 \mathrm{~mL}$ & -0.03 & 0.02 & N/A & $\mathrm{N} / \mathrm{A}$ \\
\hline $3 \mathrm{~mL}$ & 0.03 & 0.02 & 0.00 & 0.05 \\
\hline $5 \mathrm{~mL}$ & N/A & N/A & 0.00 & 0.05 \\
\hline \multicolumn{5}{|l|}{ Reconstitution device } \\
\hline Device that connects a prefilled syringe of diluent and a vial of drug & -0.08 & 0.02 & 0.01 & 0.05 \\
\hline Dual chamber syringe with diluent and drug in a single device & 0.08 & 0.02 & -0.01 & 0.05 \\
\hline \multicolumn{5}{|l|}{ Manufacturer } \\
\hline New manufacturer; unfamiliar with it & -0.34 & 0.03 & -0.30 & 0.06 \\
\hline Familiar with manufacturer and its products & 0.34 & 0.03 & 0.30 & 0.06 \\
\hline
\end{tabular}

Abbreviation: SE, standard error of the mean.

those evaluating hemophilia A treatments, the impact on preferences of moving from the three administrations per week to twice per week was as positive $(0.91)$ as moving from one bleed per year to three was negative $(-0.85)$. The pattern is similar for hemophilia $\mathrm{B}$, where the positive impact of reducing administrations from two to one per week $(0.57)$ is larger than the positive impact of eliminating a bleed (0.39), though the smaller sample of hemophilia B respondents made the estimates of the part-worth utilities less precise than those for hemophilia A and conclusions more tentative.

The present study is unique in research on patient treatment preferences in hemophilia for incorporating both efficacy for breakthrough bleeding and frequency of administration. Earlier work incorporating both attributes has been limited to physicians and has included more frequent administration - with a minimum of two to three times per week - than the current study. ${ }^{25}$ Other research on patient preferences has used similar frequencies for frequency of administration but has not incorporated efficacy. ${ }^{28}$ Another distinguishing feature is the monadic design incorporating willingness to switch rather than discrete choice; monadic rating may better reflect a decision to switch treatment than a stated choice task where respondents choose between two or more presented alternatives. Some previous conjoint exercises have included a larger number of attributes, whereas the current study focused on precisely measuring a few attributes that would be expected to vary across treatments in the near future, instructing participants to assume that cost, viral safety, risk of inhibitor development, and method of distribution (in Australia only) are similar to the product currently used.

As with any conjoint analysis, results depend on the attributes included and levels chosen for each attribute. In particular, bleeding rates included in the conjoint were sourced from clinical trials of currently available recombinant factor product and a newly developed long-acting factor product ${ }^{32-39}$ and were low relative to patient-reported bleed rates. Therefore, changes in bleed rates not included in the conjoint may be more impactful than the ones included here, and this is an important limitation of the present study. Further research assessing these attributes but incorporating higher, "real-world" bleed rates is warranted. Also, some regimens currently being studied were not included in the conjoint, such as daily low-dose prophylaxis. As with any conjoint study, the decisions were hypothetical and may differ from choices made in real life with real consequences. Likewise, results may be less applicable in decisions in which tradeoffs must be made regarding viral safety, risk of inhibitor 
development, cost, or method of distribution, though these are all similar from a patient's perspective across recently developed products, allowing the present study to focus on attributes that actually vary across treatments. These results also indicate that the company that produces the factor is an important driver of willingness to switch prophylaxis treatments for patients and parents of children with hemophilia.

\section{Conclusion}

Frequency of administration has a substantial impact on preferences for prophylactic regimen for hemophilia when concerns of viral safety, out-of-pocket cost, and risk of inhibitor development are equal across treatment regimens. Ratings of intention to switch treatments among adults with hemophilia and the parents of children with hemophilia suggest that reducing the number of infusions per week has a larger impact on treatment choice than the small differences in efficacy demonstrated between products in clinical trials.

\section{Acknowledgments}

The authors would like to thank Duygu Bozkaya at Xcenda for editorial assistance and Claire Lethbridge and Rachel Crockett at Kantar Health for their work in developing the survey. This study was conducted by Kantar Health with funding from Biogen.

\section{Disclosure}

Jeffrey Vietri and Roberto Furlan are employees of Kantar Health, and Sangeeta Krishnan is an employee and shareholder of Biogen. The authors report no other conflicts of interest in this work.

\section{References}

1. Berntorp E. Joint outcomes in patients with haemophilia: the importance of adherence to preventive regimens. Haemophilia. 2009;15: 1219-1227.

2. Barr RD, Saleh M, Furlong W, et al. Health status and health-related quality of life associated with hemophilia. Am J Hematol. 2002;71(3): $152-160$.

3. Siboni SM, Mannucci PM, Gringeri A, et al. Italian Association of Haemophilia Centers (AICE). Health status and quality of life of elderly persons with severe hemophilia born before the advent of modern replacement therapy. J Thromb Haemost. 2009;7:780-786.

4. DeKoven M, Wisniewski T, Petrilla A, et al. Health-related quality of life in haemophilia patients with inhibitors and their caregivers. Haemophilia. 2013;19:287-293.

5. van den Berg HM, Fischer K, van der Bom JG. Comparing outcomes of different treatment regimens for severe haemophilia. Haemophilia. 2003;9(suppl 1):27-31; discussion 31.

6. Coppola A, Di Capua M, De Simone C. Primary prophylaxis in children with haemophilia. Blood Transfus. 2008;6(suppl 2):S4-S11.

7. Coppola A, Tagliaferri A, Di Capua M, Franchini M. Prophylaxis in children with hemophilia: evidence-based achievements, old and new challenges. Semin Thromb Hemost. 2012;38:79-94.
8. Gringeri A, Leissinger C, Cortesi PA, et al. Health-related quality of life in patients with haemophilia and inhibitors on prophylaxis with anti-inhibitor complex concentrate: results from the Pro-FEIBA study. Haemophilia. 2013;19(5):736-743.

9. Khawaji M, Astermark J, Berntorp E. Lifelong prophylaxis in a large cohort of adult patients with severe haemophilia: a beneficial effect on orthopaedic outcome and quality of life. Eur J Haematol. 2012;88: 329-335.

10. Mondorf W, Kalnins W, Klamroth R. Patient-reported outcomes of 182 adults with severe haemophilia in Germany comparing prophylactic vs. on-demand replacement therapy. Haemophilia. 2013;19:558-563.

11. Schramm W, Royal S, Kroner B, et al. Clinical outcomes and resource utilization associated with haemophilia care in Europe. Haemophilia. 2002;8:33-43.

12. Liou WS, Tu TC, Cheng SN, et al. Secondary prophylaxis treatment versus on-demand treatment for patients with severe haemophilia A: comparisons of cost and outcomes in Taiwan. Haemophilia. 2011;17: 45-54.

13. Aledort LM, Haschmeyer RH, Pettersson H. A longitudinal study of orthopaedic outcomes for severe factor-VIII-deficient haemophiliacs. The Orthopaedic Outcome Study Group. J Intern Med. 1994; 236:391-399.

14. Ragni MV, Fogarty PJ, Josephson NC, Neff AT, Raffini LJ, Kessler CM. Survey of current prophylaxis practices and bleeding characteristics of children with severe haemophilia A in US haemophilia treatment centres. Haemophilia. 2012;18:63-68.

15. Ono O, Suzuki Y, Yosikawa K, et al. Assessment of haemophilia treatment practice pattern in Japan. Haemophilia. 2009;15:1032-1038.

16. Thornburg CD, Carpenter S, Zappa S, Munn J, Leissinger C. Current prescription of prophylactic factor infusions and perceived adherence for children and adolescents with haemophilia: a survey of haemophilia healthcare professionals in the United States. Haemophilia. 2012;18: 568-574.

17. Thornburg CD, Pipe SW. Adherence to prophylactic infusions of factor VIII or factor IX for haemophilia. Haemophilia. 2006;12:198-199.

18. De Moerloose P, Urbancik W, Van Den Berg HM, Richards M. A survey of adherence to haemophilia therapy in six European countries: results and recommendations. Haemophilia. 2008;14:931-938.

19. du Treil S, Rice J, Leissinger CA. Quantifying adherence to treatment and its relationship to quality of life in a well-characterized haemophilia population. Haemophilia. 2007;13:493-501.

20. Saxena K. Barriers and perceived limitations to early treatment of hemophilia. J Blood Med. 2013;4:49-56.

21. Zappa S, McDaniel M, Marandola J, Allen G. Treatment trends for haemophilia A and haemophilia B in the United States: results from the 2010 practice patterns survey. Haemophilia. 2012;18:e140-e153.

22. Fischer K, Van Der Bom JG, Prejs R, et al. Discontinuation of prophylactic therapy in severe haemophilia: incidence and effects on outcome. Haemophilia. 2001;7:544-550.

23. Shapiro A. Development of long-acting recombinant FVIII and FIX Fc fusion proteins for the management of hemophilia. Expert Opin Biol Ther. 2013;13:1287-1297.

24. Lee WC, Joshi AV, Woolford S, et al. Physicians' preferences towards coagulation factor concentrates in the treatment of Haemophilia with inhibitors: a discrete choice experiment. Haemophilia. 2008;14:454-465.

25. Gelhorn H, Merikle E, Krishnan S, Nemes L, Leissinger C, Valentino L. Physician preferences for medication attributes for the prophylactic treatment of patients with severe haemophilia A with inhibitors to factor VIII. Haemophilia. 2013;19:119-125.

26. Scalone L, Mantovani LG, Borghetti F, Von Mackensen S, Gringeri A. Patients', physicians', and pharmacists' preferences towards coagulation factor concentrates to treat haemophilia with inhibitors: results from the COHIBA Study. Haemophilia. 2009;15:473-486.

27. Mantovani LG, Monzini MS, Mannucci PM, Scalone L, Villa M, Gringeri A. Differences between patients', physicians' and pharmacists' preferences for treatment products in haemophilia: a discrete choice experiment. Haemophilia. 2005;11:589-597. 
28. Brown TM, Pashos CL, Joshi AV, Lee WC. The perspective of patients with haemophilia with inhibitors and their care givers: preferences for treatment characteristics. Haemophilia. 2011;17:476-482.

29. World Federation of Hemophilia. Report on the Annual Gobal Survey 2013. Montreal, Quebec, Canada: Wordl Federation of Hemophilia; 2014.

30. Kuhfeld WF, Tobias RD, Garratt M. Efficient experimental design with marketing research applications. J Mark Res. 1994;31:545-557.

31. Rossi PE, Allenby GM, McCulloch R. Bayesian Statistics and Marketing. West Sussex, England: John Wiley \& Sons, Ltd.; 2005.

32. Demia Studio Associato. R-sw conjoint: a package for advanced conjoint analysis; 2012. Available from: http://www.demia.it/softwaresolution/r-sw-conjoint/. Accessed December 15, 2012.

33. Green PE, Srinivasan V. Conjoint analysis in consumer research: issues and outlook. J Consum Res. 1978;5:103-123.

34. Mahlangu J, Powell JS, Ragni MV, et al; A-LONG Investigators. Phase 3 study of recombinant factor VIII fusion protein in severe hemophilia A. Blood. 2014;123(3):317-325.

35. Tarantino MD, Collins PW, Hay CR, et al. Clinical evaluation of an advanced category antihaemophilic factor prepared using a plasma/ albumin-free method: pharmacokinetics, efficacy, and safety in previously treated patients with haemophilia A. Haemophilia. 2004;10(5): $428-437$.
36. Valentino LA, Mamonov V, Hellmann A, et al; Prophylaxis Study Group. A randomized comparison of two prophylaxis regimens and a paired comparison of on-demand and prophylaxis treatments in hemophilia A management. J Thromb Haemost. 2012;10:359-367.

37. Powell JS, Pasi KJ, Ragni MV, et al. Phase 3 study of recombinant factor IX Fc fusion protein in hemophilia B. N Engl J Med. 2013; 369(24):2313-2323.

38. Roth DA, Kessler CM, Pasi KJ, et al. Human recombinant factor IX: safety and efficacy studies in hemophilia B patients previously treated with plasma-derived factor IX concentrates. Blood. 2001;98(13): 3600-3606.

39. Pfizer. Pfizer announces positive top-line results from phase 3 study of NONACOG ALFA (BeneFIX ${ }^{\circledR}$ ) once-weekly prophylaxis for hemophilia B [press release]; 2014 [July 16]. Available from: http://press.pfizer.com/ press-release/pfizer-announces-positive-top-line-results-phase-3-studynonacog-alfa-benefix-once-wee. Accessed October 6, 2015.

40. Windyga J, Lissitchkov T, Stasyshyn O, et al. Pharmacokinetics, efficacy and safety of BAX326, a novel recombinant factor IX: a prospective, controlled, multicentre phase I/III study in previously treated patients with severe (FIX level $<1 \%$ ) or moderately severe (FIX level $\leq 2 \%$ ) haemophilia B. Haemophilia. 2014;20(1):15-24.

41. Lambert T, Recht M, Valentino LA, et al. Reformulated BeneFix: efficacy and safety in previously treated patients with moderately severe to severe haemophilia B. Haemophilia. 2007;13:233-243.
Patient Preference and Adherence

\section{Publish your work in this journal}

Patient Preference and Adherence is an international, peer-reviewed, open access journal that focuses on the growing importance of patient preference and adherence throughout the therapeutic continuum. Patient satisfaction, acceptability, quality of life, compliance, persistence and their role in developing new therapeutic modalities and compounds to optimize

\section{Dovepress}

clinical outcomes for existing disease states are major areas of interest for the journal. This journal has been accepted for indexing on PubMed Central. The manuscript management system is completely online and includes a very quick and fair peer-review system, which is all easy to use. Visit http://www. dovepress.com/testimonials.php to read real quotes from published authors. 